\title{
Protection of stainless steel in sulfuric acid solution containing hydrogen sulfide by inhibitors
}

\author{
Ya.G. Avdeev, ${ }^{1}{ }^{*}$ L.V. Frolova, ${ }^{2}$ D.S. Kuznetsov, ${ }^{2}$ M.V. Tyurina ${ }^{1}$ \\ and M.A. Chekulaev ${ }^{1}$ \\ ${ }^{1}$ K.E. Tsiolkovsky Kaluga state university, Stepana Razina str., 26, Kaluga, \\ 248023 Russian Federation \\ ${ }^{2}$ A.N. Frumkin Institute of Physical Chemistry and Electrochemistry, Russian Academy \\ of Sciences, Leninskii pr. 31, Moscow, 119071 Russian Federation \\ *E-mail: avdeevavdeev@mail.ru
}

\begin{abstract}
The corrosion of chromium-nickel steel $1 \mathrm{Kh} 18 \mathrm{~N} 9 \mathrm{~T}$ in $2 \mathrm{M} \mathrm{H}_{2} \mathrm{SO}_{4}$ at $t=20-100^{\circ} \mathrm{C}$ was studied using the mass loss method. In addition, steel hydrogenation in the corrosive medium was measured by the vacuum extraction method. IFKhAN-92 (a 1,2,4-triazole derivative) and its combination with $\mathrm{KI}$ were studied as corrosion inhibitors. It was shown that $1 \mathrm{Kh} 18 \mathrm{~N} 9 \mathrm{~T}$ steel has low corrosion resistance in $\mathrm{H}_{2} \mathrm{SO}_{4}$ solutions, particularly at temperatures $(t)$ close to $100^{\circ} \mathrm{C}$. The steel corrosion rate is $k=1.7-727 \mathrm{~g} /\left(\mathrm{m}^{2} \cdot \mathrm{h}\right)$ under the conditions studied and increases with increasing $t$. Steel hydrogenation occurs at $t=40$ $100^{\circ} \mathrm{C}$ and is the strongest at $100^{\circ} \mathrm{C}(12 \mathrm{ml} / 100 \mathrm{~g})$. The presence of $15 \mathrm{mM} \mathrm{H}_{2} \mathrm{~S}$ in the $\mathrm{H}_{2} \mathrm{SO}_{4}$ solution slows down steel corrosion $\left(k=2.8-274 \mathrm{~g} /\left(\mathrm{m}^{2} \cdot \mathrm{h}\right)\right)$ but intensifies hydrogen absorption. The highest content of hydrogen absorbed in the metal $(36 \mathrm{ml} / 100 \mathrm{~g})$ was observed at $t=40^{\circ} \mathrm{C}$ and $1 \mathrm{~h}$ exposure of the specimens. It has been shown that, by themselves, $5 \mathrm{mM}$ IFKhAN-92 or $5 \mathrm{mM} \mathrm{KI}$ are not suitable for protection of $1 \mathrm{Kh} 18 \mathrm{~N} 9 \mathrm{~T}$ steel in the specified media, since IFKhAN-92 has low efficiency in $\mathrm{H}_{2} \mathrm{SO}_{4}$ solution without $\mathrm{H}_{2} \mathrm{~S}$, whereas, conversely, $\mathrm{KI}$ has low efficiency in $\mathrm{H}_{2} \mathrm{SO}_{4}$ solution containing $\mathrm{H}_{2} \mathrm{~S}$. However, their mixture shows versatile protection in these media. The formulation containing $2.5 \mathrm{mM}$ IFKhAN-92 $+2.5 \mathrm{mM}$ KI that suppresses steel corrosion in $\mathrm{H}_{2} \mathrm{~S}$ containing medium up to $100^{\circ} \mathrm{C}$ and totally prevents hydrogen absorption up to $60^{\circ} \mathrm{C}$, inclusive, has been recommended for steel protection in $\mathrm{H}_{2} \mathrm{SO}_{4}$, both in the absence and in the presence of $\mathrm{H}_{2} \mathrm{~S}$. This mixture is particularly efficient in solutions without $\mathrm{H}_{2} \mathrm{~S}$ where it inhibits steel corrosion in the entire $t$ range studied while keeping the content of hydrogen in the metal at metallurgical level.
\end{abstract}

Key words: acid corrosion, hydrogen sulfide, corrosion inhibitors, stainless steel, hydrogenation, triazoles.

Received: March 13, 2016. Published: April 8, 2016.

doi: $\underline{10.17675 / 2305-6894-2016-5-2-4}$ 


\section{Introduction}

As shown previously [1], inhibitory protection by formulations of a 3-substituted 1,2,4triazole (IFKhAN-92) and anionic additives (KI, KCNS, or KBr) is an efficient method for corrosion prevention of chromium-nickel stainless steels in $\mathrm{H}_{2} \mathrm{SO}_{4}$ solutions. The presence of these formulations in an acid solution makes it possible to hinder corrosion of $12 \mathrm{Kh} 18 \mathrm{~N} 10 \mathrm{~T}$ steel in $2 \mathrm{M} \mathrm{H}_{2} \mathrm{SO}_{4}$ at temperatures up to $100^{\circ} \mathrm{C}$ to a considerable extent. Of the formulations studied, the maximum protective effect is provided by the equimolar mixture of IFKhAN-92 + KI. The observed effect is based on considerable inhibition of electrode reactions on the metal in a broad range of temperatures $t$ by composite inhibitors.

Steel corrosion in acidic aqueous media is accompanied by hydrogen evolution. It often results in metal hydrogenation that can impair the mechanical properties [2]. A detailed analysis of the regularities of cathodic hydrogen evolution in acidic media and its penetration into metallic iron is given in a review [3].

Identification of the specifics of the effect of organic inhibitors of acid corrosion on steel hydrogenation remains a task of current interest. The most attention is given to studies of inhibitors belonging to quarternary ammonium salts (QAS). For example, A.I. Marshakov et al. [4,5] have shown that, unlike benzonitrile and dibutylsulfoxide, tetrabutylammonium sulfate and tetraethylammonium bromide do not change the mechanism of cathodic hydrogen evolution in acidic sulfate solutions but slow down considerably hydrogen penetration into iron. Later, L.E. Tsygankova et al. [6-8] have also shown that Catamin $\mathrm{AB}$ (a mixture of alkylbenzyldimethylammonium chlorides $\left[\mathrm{C}_{n} \mathrm{H}_{2 n+1} \mathrm{~N}^{+}\left(\mathrm{CH}_{3}\right)_{2} \mathrm{CH}_{2} \mathrm{C}_{6} \mathrm{H}_{5}\right] \mathrm{Cl}^{-}$, where $\left.n=10-18\right)$ slows down hydrogen diffusion into steel in acidic sulfate and chloride solutions. Along with corrosion inhibition of high strength steel in solutions of mineral acids, 1,2,4-triazole derivatives and formulations based thereon can slow down hydrogen absorption by the metal, thus preserving its mechanic properties [9]. In this case, the use of triazoles makes it possible to achieve more efficient hindrance of steel hydrogenation in comparison with Catamin AB that is a QAS mixture.

The presence of hydrogenation stimulators in acid solutions can considerably enhance hydrogen absorption by steel, both in case of its corrosion in such background media $[2,10]$ and in the presence of inhibitors [10]. Hydrogen sulfide that can saturate acid solutions during various production operations is the most hazardous steel hydrogenation stimulator [11-13]. The presence of hydrogen sulfide in hydrochloric acid solution enhances the corrosion of chromium-nickel steel $1 \mathrm{Kh} 18 \mathrm{~N} 9 \mathrm{~T}$ in this solution and causes metal hydrogenation. In the presence of the inhibitors studied (IFKhAN-92 and IFKhAN$92+$ urotropine formulation), steel corrosion is intensified and inhibitors are not always able to suppress metal hydrogenation completely [10].

In view of the above considerations, it seems expedient to study the liability of chromium-nickel steel $1 \mathrm{Kh} 18 \mathrm{~N} 9 \mathrm{~T}$ to hydrogenation in $\mathrm{H}_{2} \mathrm{SO}_{4}$ solutions including those containing $\mathrm{H}_{2} \mathrm{~S}$ and to estimate the effect of IFKhAN-92 and its equimolar blend with $\mathrm{KI}$ on this process. 


\section{Experimental procedure}

The corrosion rate of foil made of $1 \mathrm{Kh} 18 \mathrm{~N} 9 \mathrm{~T}$ stainless steel (composition, mass\%: $\mathrm{Fe}-$ 71.92; $\mathrm{Cr}-17.57 ; \mathrm{Ni}-9.16 ; \mathrm{Ti}-0.83 ; \mathrm{Si}-0.52)$ in $2 \mathrm{M}_{2} \mathrm{SO}_{4}$ at $t=20-100^{\circ} \mathrm{C}$ was determined from the mass loss of specimens (no less than 3 specimens per point) sized $20 \mathrm{~mm} \times 10 \mathrm{~mm} \times 0.25 \mathrm{~mm}$, using $50 \mathrm{ml}$ of the acid solution per specimen. The exposure time of the specimens in the solution was $0.25,0.5,1$, or $2 \mathrm{~h}$. Prior to an experiment, the specimens were cleaned with micron-graded polishing paper M40 and degreased with acetone.

Solutions were prepared from $\mathrm{H}_{2} \mathrm{SO}_{4}$ of "chemically pure" grade and distilled water. $\mathrm{H}_{2} \mathrm{SO}_{4}$ solutions were saturated with hydrogen sulfide $\left(\mathrm{C}_{\mathrm{H} 2 \mathrm{~S}}=15 \mathrm{mM}\right)$ obtained from $\mathrm{Na}_{2} \mathrm{~S}$ (technical grade, PRC standard: GB/T 10500-2000) and 15\% $\mathrm{H}_{2} \mathrm{SO}_{4}$ ("chemically pure" grade). The base concentrations $(C)$ of individual inhibitors and their mixtures amounted to $5.0 \mathrm{mM}$. A formulation containing $2.5 \mathrm{mM}$ IFKhAN-92 $+2.5 \mathrm{mM}$ urotropine was studied. As shown previously [1], this ratio of components is the best for protection of chromiumnickel stainless steels in $\mathrm{H}_{2} \mathrm{SO}_{4}$ solutions.

The efficiency of inhibitors was estimated from the inhibition coefficient, $\gamma=k_{0} / k_{\text {in }}$, where $k_{0}$ and $k_{\text {in }}$ are the corrosion rates in the background solution and in the solution with the additive being studied, respectively. In the case of inhibited solutions containing hydrogen sulfide, $2 \mathrm{M} \mathrm{H}_{2} \mathrm{SO}_{4}+15 \mathrm{mM} \mathrm{H}_{2} \mathrm{~S}$ was considered as the background solution. In order to estimate quantitatively the effect of additives on nitrogen-containing inhibitors, the mutual influence coefficients of the mixture components were calculated [14]:

$$
K_{m}=\frac{\gamma_{\text {mix }}}{\prod_{i=1}^{m} \gamma_{\mathrm{i}}},
$$

where $\gamma_{\text {mix }}$ is the corrosion inhibition coefficient for the inhibitor mixture and $\prod_{i=1}^{m} \gamma_{\mathrm{i}}$ is the product of the corrosion inhibition coefficients for individual mixture components. If $K_{\mathrm{m}}<1$, the protection coefficients of the inhibitor components are mutually reduced; at $K_{\mathrm{m}}=1$, additive behavior is observed; and only at $K_{\mathrm{m}}>1$ it should be concluded that the components of the inhibitor mixture mutually enhance protection.

The extent of hydrogen absorption by steel $1 \mathrm{Kh} 18 \mathrm{~N} 9 \mathrm{~T}$ was determined by vacuum extraction method. After corrosion tests, the specimens were placed in a vessel, air was evacuated from the vessel to a residual pressure of $1.33 \cdot 10^{-4} \mathrm{~Pa}$, and the vessel was heated to $t=500^{\circ} \mathrm{C}$. The amount of hydrogen evolved upon heating the specimens in vacuo was estimated from pressure change in $10 \mathrm{~min}\left(P_{\text {tot }}\right)$ measured by a McLeod manometer at a constant volume of the evacuated part of the system. The pressure of evolved hydrogen $\left(P_{\mathrm{H}_{2}}\right)$ was calculated from the change in total pressure $\left(P_{\text {tot }}\right)$ by the formula: 


$$
P_{\mathrm{H}_{2}}=P_{\text {tot }}-P_{\text {nat }},
$$

where $P_{\text {nat }}$ is the correction obtained in the blank test. The volume concentration of hydrogen in steel $(\mathrm{ml} / 100 \mathrm{~g}$ of steel) was calculated by the formula:

$$
V_{\mathrm{H}_{2}}=\frac{100 K P_{\mathrm{H}_{2}}}{M},
$$

where $K$ is a constant related to the volume of the analytical part of the set-up, and $M$ is the mass of the steel specimen in grams.

The hydrogen content in the metal is given with correction for metallurgical hydrogen, the concentration of which in $1 \mathrm{Kh} 18 \mathrm{~N} 9 \mathrm{~T}$ steel amounts to $2.0 \mathrm{ml} / 100 \mathrm{~g}$.

\section{Experimental results and discussion}

The corrosion of chromium-nickel steel in $2 \mathrm{M} \mathrm{H}_{2} \mathrm{SO}_{4}$ occurs at rates within $k=1.7-$ $727 \mathrm{~g} /\left(\mathrm{m}^{2} \cdot \mathrm{h}\right)$ and accelerates with an increase in $t$ (Figure 1). In fact, according to studies for $0.25 \mathrm{~h}$, an increase in $t$ of the acid by $80^{\circ} \mathrm{C}$ increases $k 97$-fold. Corrosion slows down with time at $t \leq 40^{\circ} \mathrm{C}$, accelerates with time at $t=60^{\circ} \mathrm{C}$, and corrosion acceleration changes to corrosion hindrance at $t=80^{\circ} \mathrm{C}$. Unfortunately, due to high $k$ values at $t=80^{\circ} \mathrm{C}$ and especially at $100^{\circ} \mathrm{C}$, we failed to obtain all the values within the selected time periods due to complete dissolution of the specimens. A similar situation is characteristic of inhibited acid solutions if the protective effect of inhibitors is low.
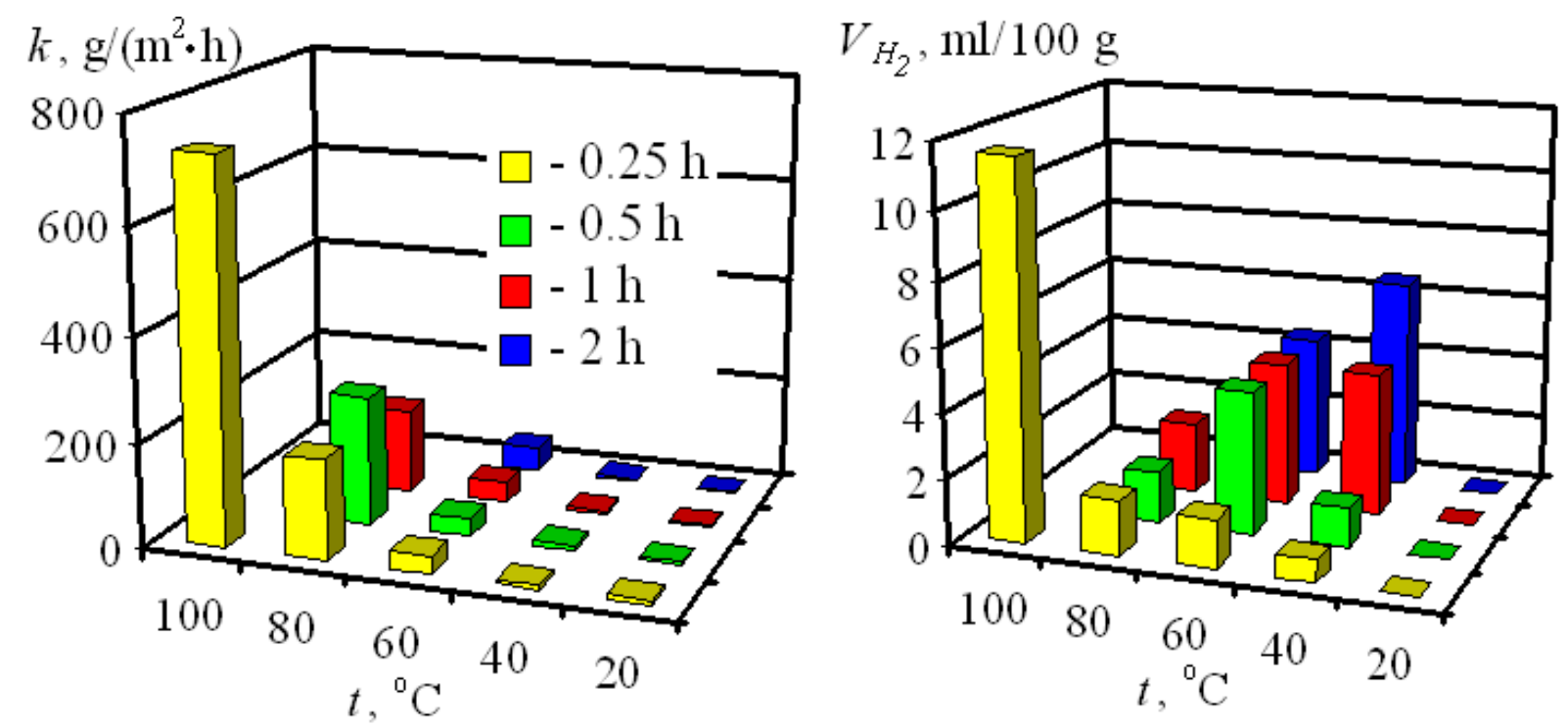

Figure 1. Corrosion rates of steel $1 \mathrm{Kh} 18 \mathrm{~N} 9 \mathrm{~T}$ in $2 \mathrm{M} \mathrm{H}_{2} \mathrm{SO}_{4}$ and volume of hydrogen absorbed by the metal as a function of specimen exposure time and solution temperature.

At $t=20^{\circ} \mathrm{C}$, stainless steel does not undergo hydrogenation even after $2 \mathrm{~h}$ exposure to $2 \mathrm{M} \mathrm{H}_{2} \mathrm{SO}_{4}$ (Figure 1). An increase in $t$ to $40^{\circ} \mathrm{C}$ results in metal hydrogenation and the hydrogen content in steel at the same exposure time of the specimens in the solution 
reaches $6.5 \mathrm{ml} / 100 \mathrm{~g}$. A further increase in $t$ results in faster steel hydrogenation but the total hydrogen content in the metal becomes lower $\left(4.4 \mathrm{ml} / 100 \mathrm{~g}\right.$ at $60^{\circ} \mathrm{C}$ and $2.2 \mathrm{ml} / 100 \mathrm{~g}$ at $80^{\circ} \mathrm{C}$ ). At $t=100^{\circ} \mathrm{C}$ where the metal corrodes with a maximum $k$, the hydrogen content in steel reaches a considerable value of $12 \mathrm{ml} / 100 \mathrm{~g}$ even in $0.25 \mathrm{~h}$. The observed complex type of dependence of hydrogen content in stainless steel on the time of specimen exposure to the acid and on $t$ can be explained by competition of two processes: hydrogen evolution on the metal surface with incorporation of a fraction of hydrogen into the metal, and dissolution of a hydrogen-saturated surface layer of the metal. The former process favors hydrogen absorption by the metal, whereas on the contrary, the latter one decreases the hydrogen content in the metal. The combined effect of these processes that are partially independent results in a complex overall picture of metal hydrogenation in the course of time and with an increase in $t$.

If the acid solution contains $15 \mathrm{mM} \mathrm{H}_{2} \mathrm{~S}$, the $k$ of steel ranges within $2.8-274 \mathrm{~g} /\left(\mathrm{m}^{2} \cdot \mathrm{h}\right)$. Hydrogen sulfide has a predominantly inhibiting effect on steel corrosion. The decrease in corrosion rate in comparison with $\mathrm{H}_{2} \mathrm{~S}$-free solutions can be up to 3.6-fold (Figure 2). It is only in the range of $t=40-60^{\circ} \mathrm{C}$ in the initial time period that corrosion rates of the metal exceed the $k$ values characteristic of $2 \mathrm{M} \mathrm{H}_{2} \mathrm{SO}_{4}$ in the absence of $\mathrm{H}_{2} \mathrm{~S}$. In general, steel corrosion rate in these solutions increases with $t$ increase but slows down with time. According to $0.25 \mathrm{~h}$ studies, a $t$ increase by $80^{\circ} \mathrm{C}$ accelerates steel corrosion 43 -fold.
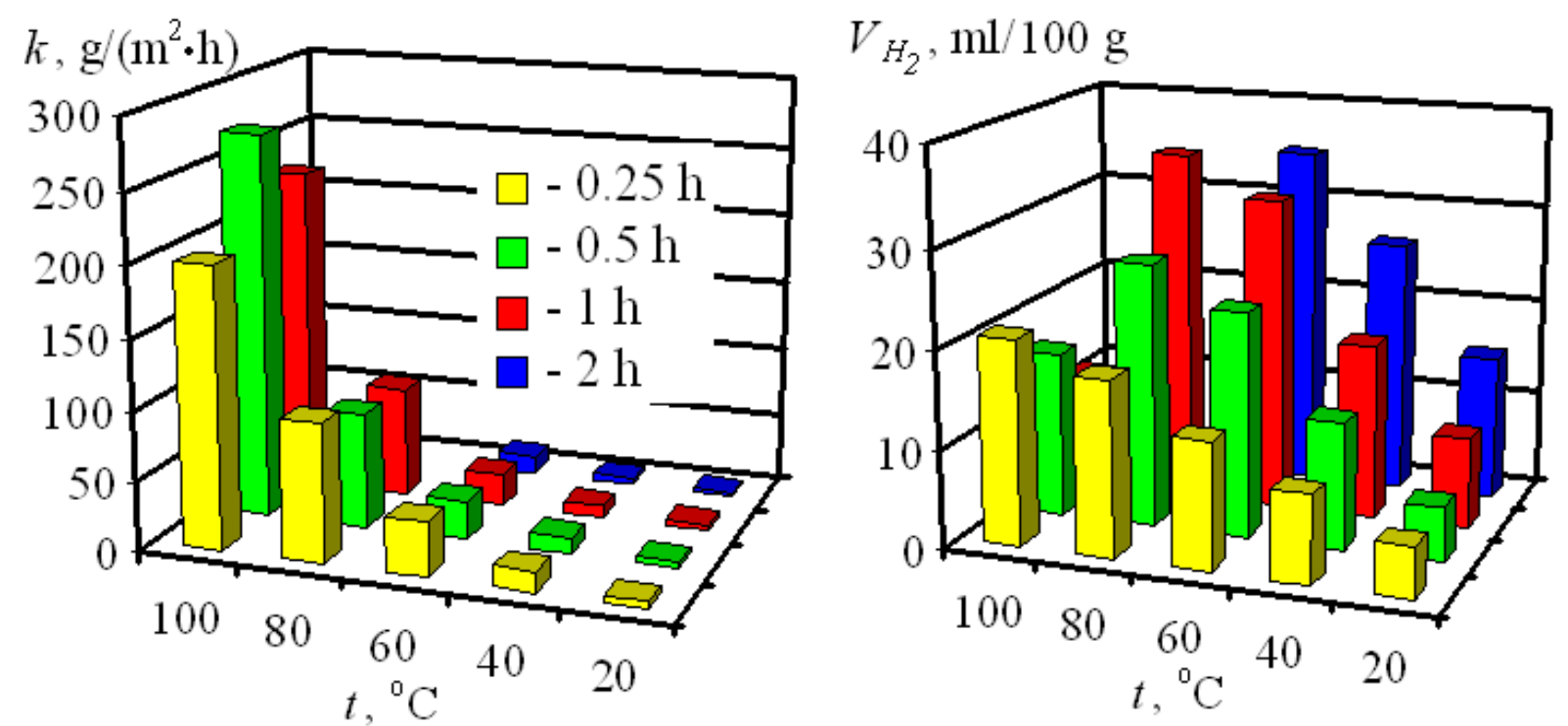

Figure 2. Corrosion rates of steel $1 \mathrm{Kh} 18 \mathrm{~N} 9 \mathrm{~T}$ in $2 \mathrm{M} \mathrm{H}_{2} \mathrm{SO}_{4}+15 \mathrm{mM} \mathrm{H}_{2} \mathrm{~S}$ and volume of hydrogen absorbed by the metal as a function of specimen exposure time and solution temperature.

At $t=20^{\circ} \mathrm{C}$, stainless steel is hydrogenated considerably in $2 \mathrm{M} \mathrm{H}_{2} \mathrm{SO}_{4}+15 \mathrm{mM} \mathrm{H}_{2} \mathrm{~S}$ even after $0.25 \mathrm{~h}$ of specimen exposure to the acid. Increasing the time of specimen exposure to the corrosive medium to $2 \mathrm{~h}$ increases the hydrogen content in the metal 2.9fold. Increasing the $t$ of the solution increases the hydrogen content in steel. The maximum 
metal hydrogenation is observed upon $0.25 \mathrm{~h}$ exposure of specimens to the solution at $t=$ $100^{\circ} \mathrm{C}$. At longer exposures, it is observed at $t=80^{\circ} \mathrm{C}$ and may reach $36 \mathrm{ml} / 100 \mathrm{~g}$ of steel, which is 3 times higher than in the $\mathrm{H}_{2} \mathrm{~S}$-free solution. At $t=20-80^{\circ} \mathrm{C}$, longer exposures of specimens to the corrosive medium enhance steel hydrogenation that decreases only at $t=$ $100^{\circ} \mathrm{C}$. This is probably due to fast steel dissolution and removal of the hydrogenated steel layer.

IFKhAN-92 by itself slows down steel corrosion only slightly in the entire range of acid solution temperatures $t(\gamma \leq 5.8)$ and $\gamma$ decreases with time (Figure 3, Table 1). Despite this, addition of $5.0 \mathrm{mM}$ IFKhAN-92 totally suppresses steel hydrogenation at $t \leq 60^{\circ} \mathrm{C}$. Beginning from $t=80^{\circ} \mathrm{C}$, the presence of hydrogen is detected in steel. It reaches $7.2 \mathrm{ml} / 100 \mathrm{~g}$ at $100^{\circ} \mathrm{C}$.
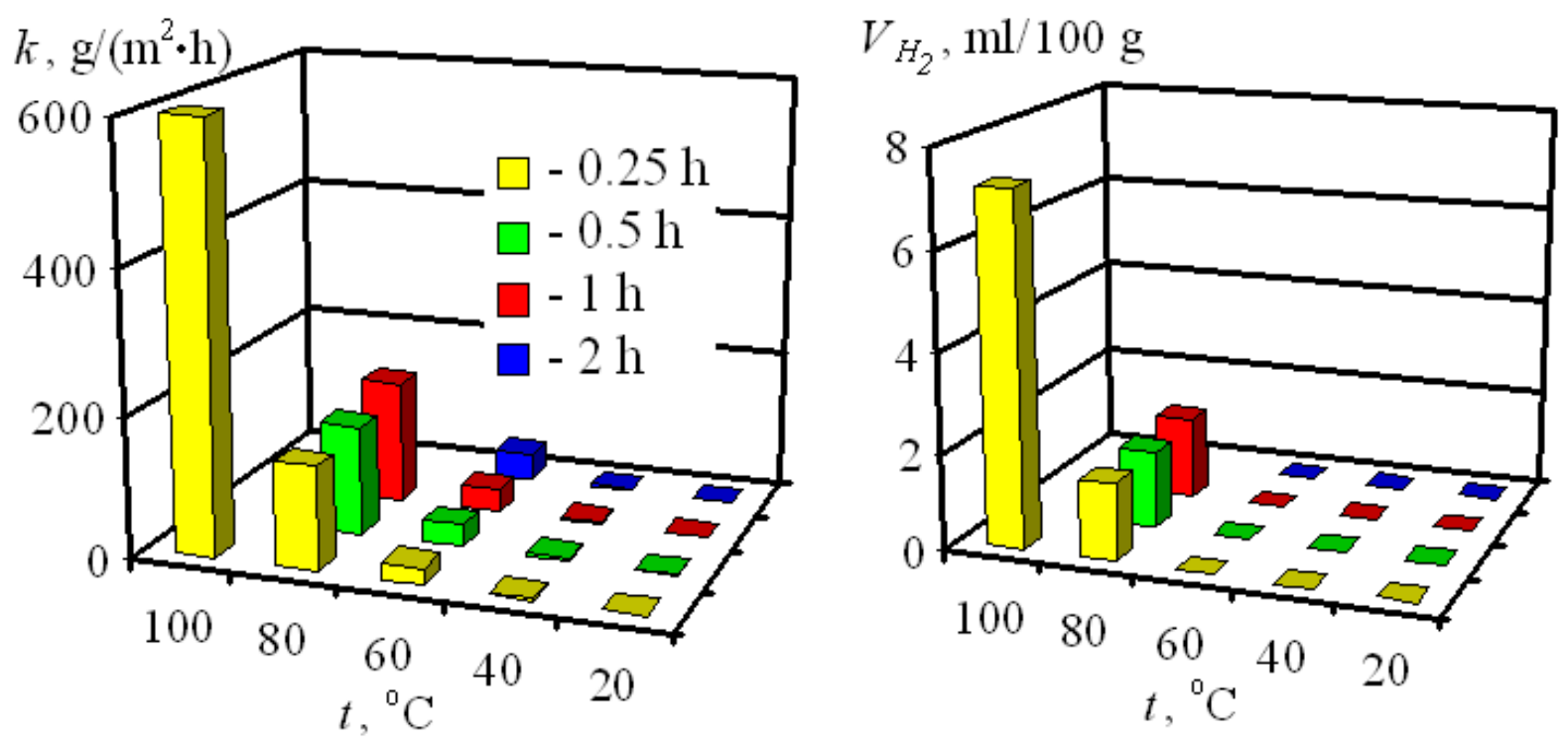

Figure 3. Corrosion rates of steel $1 \mathrm{Kh} 18 \mathrm{~N} 9 \mathrm{~T}$ in $2 \mathrm{M} \mathrm{H}_{2} \mathrm{SO}_{4}$ containing $5 \mathrm{mM}$ IFKhAN-92 and volume of hydrogen absorbed by the metal as a function of specimen exposure time and solution temperature.

Conversely, addition of IFKhAN-92 to $\mathrm{H}_{2} \mathrm{~S}$-containing solutions efficiently slows down steel corrosion 11-144 fold (Figure 4). In this case, coefficient $\gamma$ increases with $t$ increase up to $100^{\circ} \mathrm{C}$, as it is typical of high-temperature corrosion inhibitors [15]. The high efficiency of IFKhAN-92 in this medium results from its joint effect with $\mathrm{H}_{2} \mathrm{~S}$ on the corrosion process. Previously we noted that the protective effect of IFKhAN-92 in acid media can be improved considerably by hydrophobic sulfur-containing additives, including sodium sulfide that is converted to $\mathrm{H}_{2} \mathrm{~S}$ in acidic media [16]. Though steel corrosion is efficiently hindered under these conditions, it is noted that metal hydrogenation occurs starting from $60^{\circ} \mathrm{C}$ and increases with $t$ rise and in the course of time. The maximum hydrogen content in steel is observed at $100^{\circ} \mathrm{C}$ and amounts to $11 \mathrm{ml} / 100 \mathrm{~g}$. 

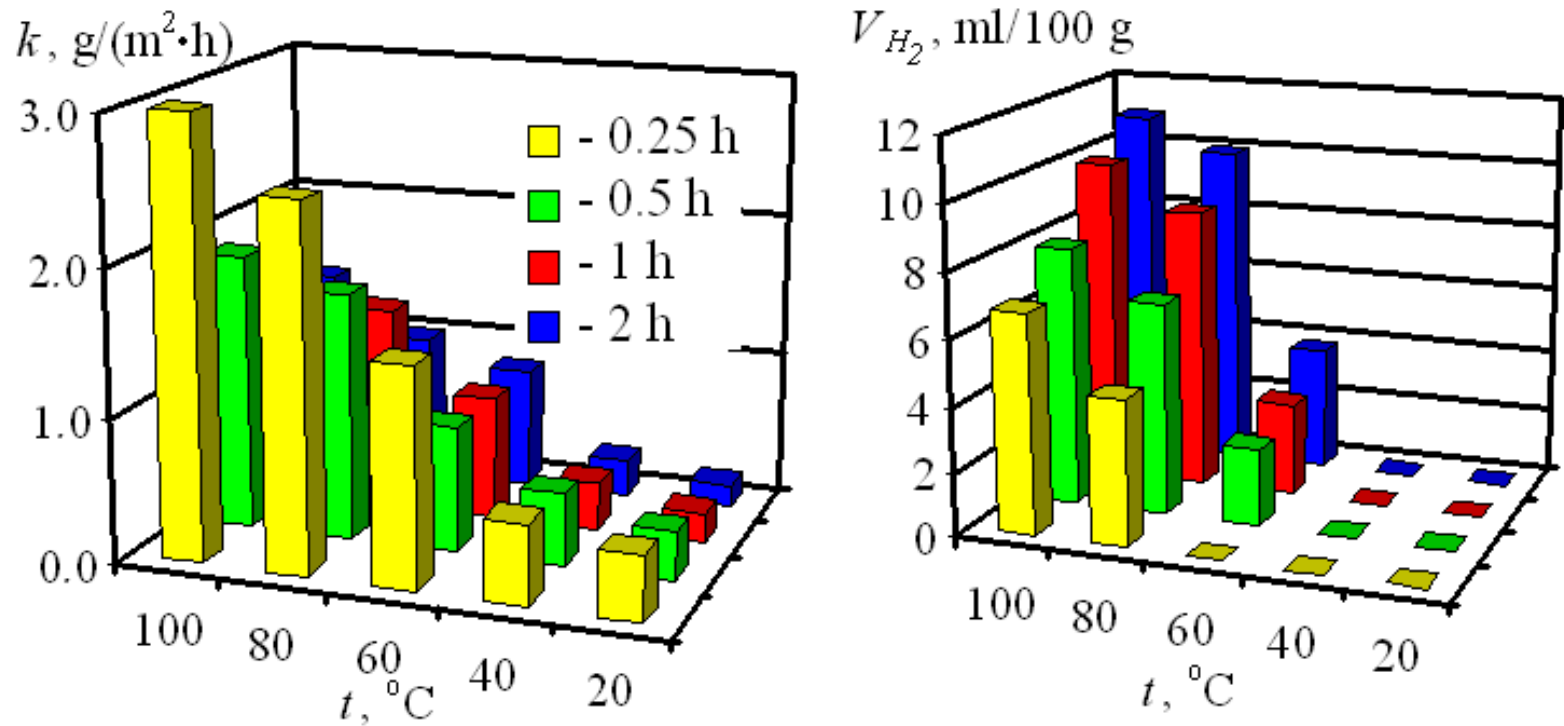

Figure 4. Corrosion rates of steel $1 \mathrm{Kh} 18 \mathrm{~N} 9 \mathrm{~T}$ in $2 \mathrm{M} \mathrm{H}_{2} \mathrm{SO}_{4}+15 \mathrm{mM} \mathrm{H}_{2} \mathrm{~S}$ containing $5 \mathrm{mM}$ IFKhAN-92 and volume of hydrogen absorbed by the metal as a function of specimen exposure time and solution temperature.

$\mathrm{KI}$ itself is efficient as a steel corrosion inhibitor in $\mathrm{H}_{2} \mathrm{SO}_{4}$ solutions (Figure $5 a$ ). At all $t$ values studied, it slows down corrosion 15-404 fold, and the maximum $k$ in the presence of this compound is no higher than $1.8 \mathrm{~g} /\left(\mathrm{m}^{2} \cdot \mathrm{h}\right)$. The temperature maximum of efficiency of this additive is not reached at least up to $100^{\circ} \mathrm{C}$, which also characterizes it as a high-temperature corrosion inhibitor of $1 \mathrm{Kh} 18 \mathrm{~N} 9 \mathrm{~T}$ steel in $\mathrm{H}_{2} \mathrm{SO}_{4}$ solution. The presence of KI slows down steel corrosion with time, whereas $5.0 \mathrm{mM}$ KI also completely suppresses steel hydrogenation in the entire $t$ range studied.
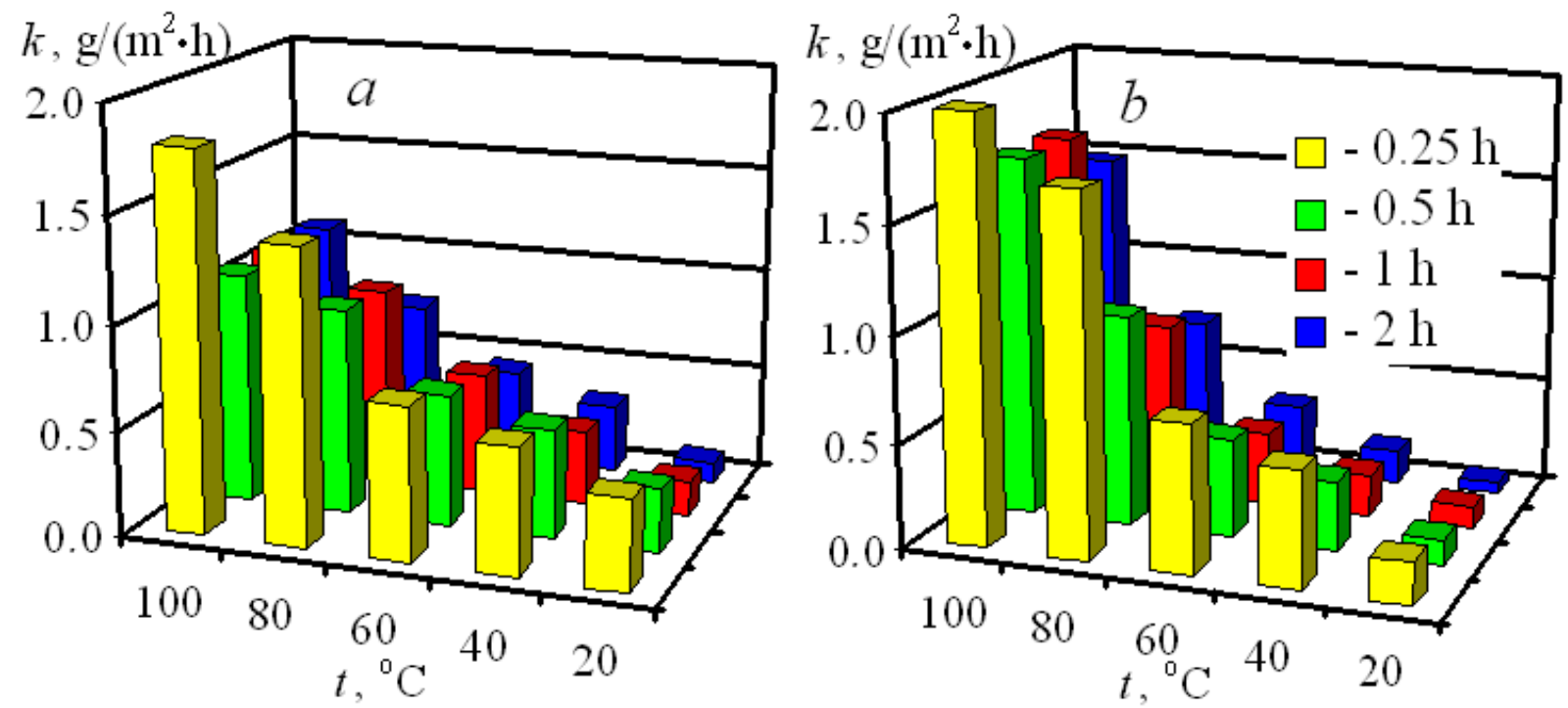

Figure 5. Corrosion rates of steel $1 \mathrm{Kh} 18 \mathrm{~N} 9 \mathrm{~T}$ in $2 \mathrm{M} \mathrm{H}_{2} \mathrm{SO}_{4}$ containing $5 \mathrm{mM} \mathrm{KI}$ (a) and $2.5 \mathrm{mM}$ IFKhAN-92 $+2.5 \mathrm{mM} \mathrm{KI}(\mathrm{b})$ as a function of specimen exposure time and solution temperature. 
Table 1. Corrosion inhibition coefficients $(\gamma)$ of steel $1 \mathrm{Kh} 18 \mathrm{~N} 9 \mathrm{~T}$ in $2 \mathrm{M} \mathrm{H}_{2} \mathrm{SO}_{4}$ provided by inhibitors at various temperatures and exposure times.

\begin{tabular}{|c|c|c|c|c|c|c|}
\hline \multirow{2}{*}{ Inhibitor } & \multirow[t]{2}{*}{$\tau, \mathbf{h}$} & \multicolumn{5}{|c|}{$\gamma$ values at various temperatures, ${ }^{\circ} \mathrm{C}$} \\
\hline & & 20 & 40 & 60 & 80 & 100 \\
\hline \multicolumn{7}{|c|}{ Without $\mathrm{H}_{2} \mathrm{~S}$} \\
\hline \multirow{4}{*}{5 mM IFKhAN-92 } & 0.25 & 5.8 & 2.6 & 1.5 & 1.3 & 1.2 \\
\hline & 0.5 & 5.8 & 2.4 & 1.2 & 1.6 & - \\
\hline & 1.0 & 3.4 & 2.1 & 1.2 & 0.93 & - \\
\hline & 2.0 & 2.1 & 1.4 & 1.2 & - & - \\
\hline \multirow{4}{*}{$5 \mathrm{mM} \mathrm{KI}$} & 0.25 & 17 & 15 & 49 & 136 & 404 \\
\hline & 0.5 & 17 & 16 & 60 & 252 & - \\
\hline & 1.0 & 16 & 22 & 71 & 171 & - \\
\hline & 2.0 & 17 & 18 & 104 & - & - \\
\hline \multirow{4}{*}{$2.5 \mathrm{mM}$ IFKhAN-92 + $2.5 \mathrm{mM} \mathrm{KI}$} & 0.25 & 38 & 16 & 51 & 112 & 364 \\
\hline & 0.5 & 43 & 26 & 81 & 247 & - \\
\hline & 1.0 & 28 & 39 & 117 & 196 & - \\
\hline & 2.0 & 28 & 38 & 142 & - & - \\
\hline \multicolumn{7}{|c|}{$15 \mathrm{mM} \mathrm{H}_{2} \mathrm{~S}$} \\
\hline \multirow{4}{*}{5 mM IFKhAN-92 } & 0.25 & 11 & 27 & 26 & 40 & 67 \\
\hline & 0.5 & 14 & 22 & 32 & 48 & 144 \\
\hline & 1.0 & 20 & 26 & 27 & 56 & 144 \\
\hline & 2.0 & 18 & 18 & 15 & - & - \\
\hline \multirow{4}{*}{$5 \mathrm{mM} \mathrm{KI}$} & 0.25 & 0.98 & 1.4 & 2.2 & 4.7 & 1.1 \\
\hline & 0.5 & 1.0 & 1.1 & 1.4 & 2.0 & 1.7 \\
\hline & 1.0 & 1.1 & 0.98 & 0.88 & 0.86 & 1.7 \\
\hline & 2.0 & 1.0 & 0.72 & 0.72 & - & - \\
\hline \multirow{4}{*}{$2.5 \mathrm{mM}$ IFKhAN-92 + $2.5 \mathrm{mM} \mathrm{KI}$} & 0.25 & 16 & 44 & 98 & 83 & 59 \\
\hline & 0.5 & 9.4 & 21 & 49 & 59 & 137 \\
\hline & 1.0 & 15 & 24 & 40 & 61 & 154 \\
\hline & 2.0 & 15 & 17 & 30 & - & - \\
\hline
\end{tabular}


Addition of $15 \mathrm{mM} \mathrm{H}_{2} \mathrm{~S}$ to $2 \mathrm{M} \mathrm{H}_{2} \mathrm{SO}_{4}+5 \mathrm{mM} \mathrm{KI}$ solution can accelerate steel corrosion up to 144-fold (Figure 6). In this case KI, which efficiently suppresses steel corrosion and hydrogenation in $\mathrm{H}_{2} \mathrm{SO}_{4}$ itself, loses its protective properties and the maximum decrease in the $k$ of steel provided by it becomes $\gamma \leq 4.7$. The $\gamma$ values observed in $\mathrm{H}_{2} \mathrm{SO}_{4}$ solutions without $\mathrm{H}_{2} \mathrm{~S}$ are 11-367 times higher than in its presence. Steel hydrogenation is also observed. It increases with time and with $t$ increase up to $80^{\circ} \mathrm{C}$. In this case, the maximum hydrogen content of steel can be comparable to that in the background solutions, namely, $38 \mathrm{ml} / 100 \mathrm{~g}$. Apparently, the insignificant decrease in hydrogen content in steel at $100^{\circ} \mathrm{C}$ is also due to its dissolution and removal of the hydrogenated steel layer.
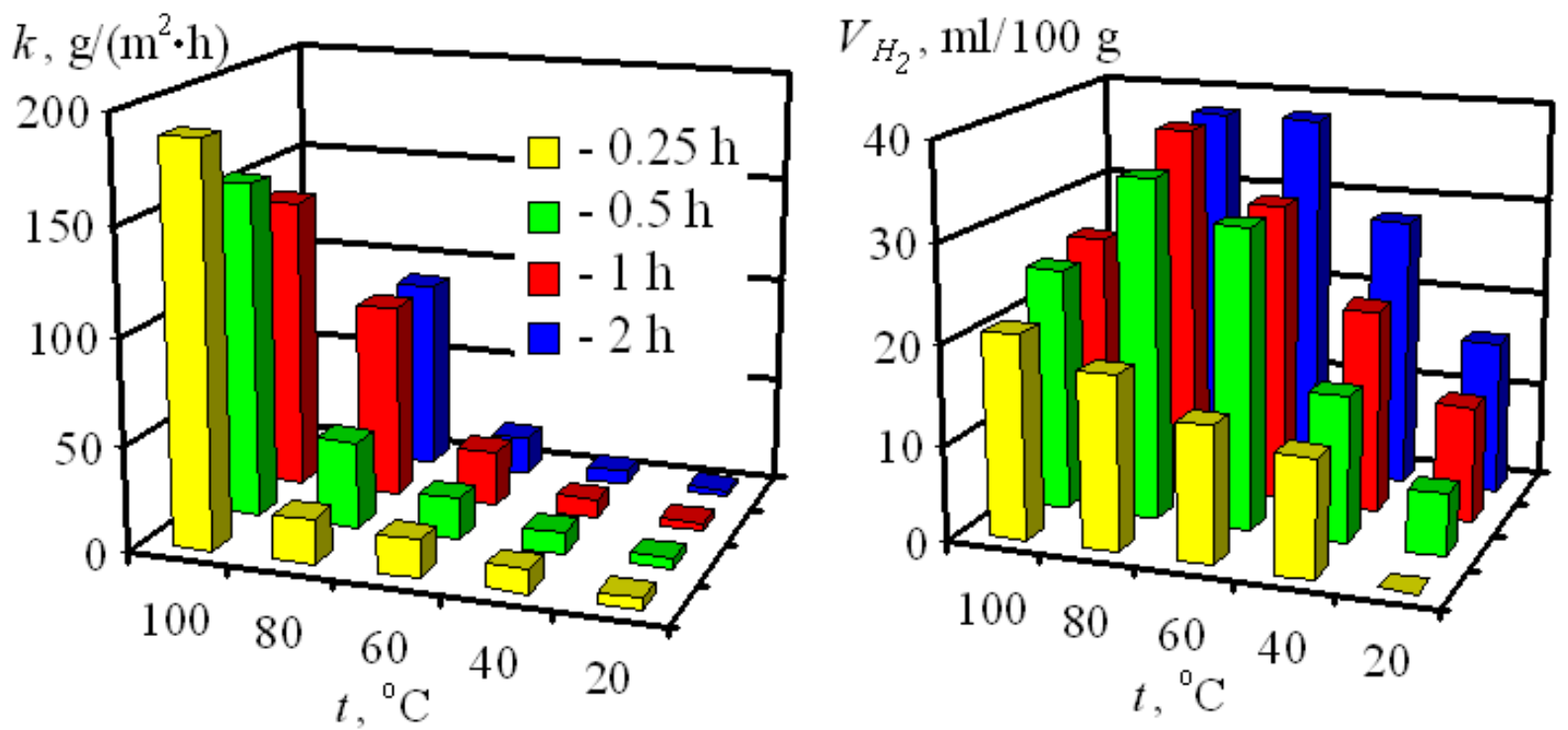

Figure 6. Corrosion rates of steel $1 \mathrm{Kh} 18 \mathrm{~N} 9 \mathrm{~T}$ in $2 \mathrm{M} \mathrm{H}_{2} \mathrm{SO}_{4}+15 \mathrm{mM} \mathrm{H}_{2} \mathrm{~S}$ containing $5 \mathrm{mM}$ $\mathrm{KI}$ and volume of hydrogen absorbed by the metal as a function of specimen exposure time and solution temperature.

The protective effect of an equimolar mixture of IFKhAN-92 and KI (5.0 mM) in $2 \mathrm{M}$ $\mathrm{H}_{2} \mathrm{SO}_{4}$ at $t \leq 60^{\circ} \mathrm{C}$ exceeds those of its components, i.e., KI and particularly IFKhAN-92 (Figure $5 b$ ). KI is somewhat more efficient at higher $t$. In fact, the $k$ of steel in a solution inhibited by $5.0 \mathrm{mM}$ of the mixed inhibitor at $t=100^{\circ} \mathrm{C}$ is $1.1-1.5$ times higher than that in the acid containing 5.0 mM KI. However, corrosion is hindered 16-364 fold in the presence of the mixed inhibitor $\left(t=20-100^{\circ} \mathrm{C}\right)$ and $k \leq 2 \mathrm{~g} /\left(\mathrm{m}^{2} \cdot \mathrm{h}\right)$. The inhibitor also hinders steel corrosion in time. The growth of the $\gamma$ coefficient of the formulation up to $100^{\circ} \mathrm{C}$ allows us to consider it as a high-temperature inhibitor. The mixture components predominantly manifest an antagonism of action, though it becomes weaker with time (Table 2). In many respects, the antagonism of action of the components of this inhibitor mixture in $\mathrm{H}_{2} \mathrm{SO}_{4}$ without $\mathrm{H}_{2} \mathrm{~S}$ is determined by the high inhibitive effect of one of its components, namely KI. The hydrogen content in all steel samples exposed to the acid solution with addition of $2.5 \mathrm{mM}$ IFKhAN-92 $+2.5 \mathrm{mM}$ KI remains at metallurgical level. 
Table 2. Mutual influence coefficients $\left(K_{m}\right)$ of inhibitor mixtures $2.5 \mathrm{mM}$ IFKhAN-92 $+2.5 \mathrm{mM}$ KI at various temperatures and exposure times.

\begin{tabular}{cccccc}
\hline \multirow{2}{*}{$\boldsymbol{\tau} \mathbf{h}$} & \multicolumn{5}{c}{$\boldsymbol{K}_{\boldsymbol{m}}$ values at various temperatures, ${ }^{\circ} \mathbf{C}$} \\
\cline { 2 - 6 } & $\mathbf{2 0}$ & $\mathbf{4 0}$ & $\mathbf{6 0}$ & $\mathbf{8 0}$ & $\mathbf{1 0 0}$ \\
\hline 0.25 & 0.39 & 0.41 & 0.69 & 0.63 & 0.75 \\
0.5 & 0.44 & 0.68 & 1.1 & 0.61 & - \\
1.0 & 0.51 & 0.84 & 1.4 & 1.2 & - \\
2.0 & 0.78 & 1.5 & 1.1 & - & - \\
\hline 0.25 & 1.3 & & $15 \mathrm{mM} \mathrm{H}_{2} \mathrm{~S}$ & 1.7 & 0.43 \\
0.5 & 0.67 & 1.2 & 1.1 & 0.61 & 0.56 \\
1.0 & 0.68 & 0.87 & 1.7 & 1.3 & 0.63 \\
2.0 & 0.85 & 1.2 & 2.8 & - & - \\
\hline
\end{tabular}

The protective effect of $2.5 \mathrm{mM}$ IFKhAN-92 $+2.5 \mathrm{mM} \mathrm{KI}$ in $2 \mathrm{M} \mathrm{H}_{2} \mathrm{SO}_{4}+15 \mathrm{mM}$ $\mathrm{H}_{2} \mathrm{~S}$ is comparable to that of $5 \mathrm{mM}$ IFKhAN-92 alone and is much higher than that of 5 $\mathrm{mM} \mathrm{KI}$ alone (Figure 7). The mixed inhibitor slows down steel corrosion 9.4-154 fold, while the maximum $k$ value is $\leq 3.4 \mathrm{~g} /\left(\mathrm{m}^{2} \cdot \mathrm{h}\right)$, which is somewhat higher than that in the solution without $\mathrm{H}_{2} \mathrm{~S}$. The mixture components mostly manifest antagonism of action at $t=$ 20,80 and $100^{\circ} \mathrm{C}$ and synergism with low $K_{\mathrm{m}}$ values at $t=40$ and $60^{\circ} \mathrm{C}$ (Table 2). Unlike in the acid solutions containing no $\mathrm{H}_{2} \mathrm{~S}$, the antagonism of action of the components of this inhibitor mixture is mainly determined by the high inhibitive effect of IFKhAN-92, rather than $\mathrm{KI}$, in this medium. The hydrogen content in steel specimens exposed to $2 \mathrm{M} \mathrm{H}_{2} \mathrm{SO}_{4}+$ $15 \mathrm{mM} \mathrm{H}_{2} \mathrm{~S}+2.5 \mathrm{mM}$ IFKhAN-92 $+2.5 \mathrm{mM} \mathrm{KI}$ at $t \leq 60^{\circ} \mathrm{C}$ remains at metallurgical level. Some hydrogenation of specimens is only observed at higher solution temperatures, with a maximum of $9.3 \mathrm{ml} / 100 \mathrm{~g}$ of the metal at $100^{\circ} \mathrm{C}$. It should be noted that it is the smallest value of maximum hydrogenation that we observed in hydrogen sulfidecontaining media. It is 3.9 times smaller than the value observed in the background solution, 4.1 times smaller than the value characteristic of the solution inhibited with $5 \mathrm{mM}$ $\mathrm{KI}$, and 1.2 times better than the value obtained in the medium inhibited with $5 \mathrm{mM}$ IFKhAN-92. In this case, unlike in $2 \mathrm{M} \mathrm{H}_{2} \mathrm{SO}_{4}+15 \mathrm{mM} \mathrm{H}_{2} \mathrm{~S}+5 \mathrm{mM}$ IFKhAN-92, the absence of hydrogenation is observed up to $60^{\circ} \mathrm{C}$ rather than up to $40^{\circ} \mathrm{C}$.

Our study allowed us to find an interesting phenomenon. Addition of a small amount of $\mathrm{H}_{2} \mathrm{~S}$ to the $\mathrm{H}_{2} \mathrm{SO}_{4}$ solution drastically changes the behavior of corrosion inhibitors. KI that efficiently protects steel in the absence of $\mathrm{H}_{2} \mathrm{~S}$ nearly loses this property if $\mathrm{H}_{2} \mathrm{~S}$ is present. Conversely, the substituted triazole acquires a high protective effect in the $\mathrm{H}_{2} \mathrm{~S}$ - 
containing medium. From this perspective, the composite inhibitor that retains the properties of $\mathrm{KI}$ in $\mathrm{H}_{2} \mathrm{SO}_{4}$ and the properties of IFKhAN-92 in $\mathrm{H}_{2} \mathrm{SO}_{4}+\mathrm{H}_{2} \mathrm{~S}$ appears interesting. It is efficient in both media and allows steel hydrogenation to be minimized in these media.
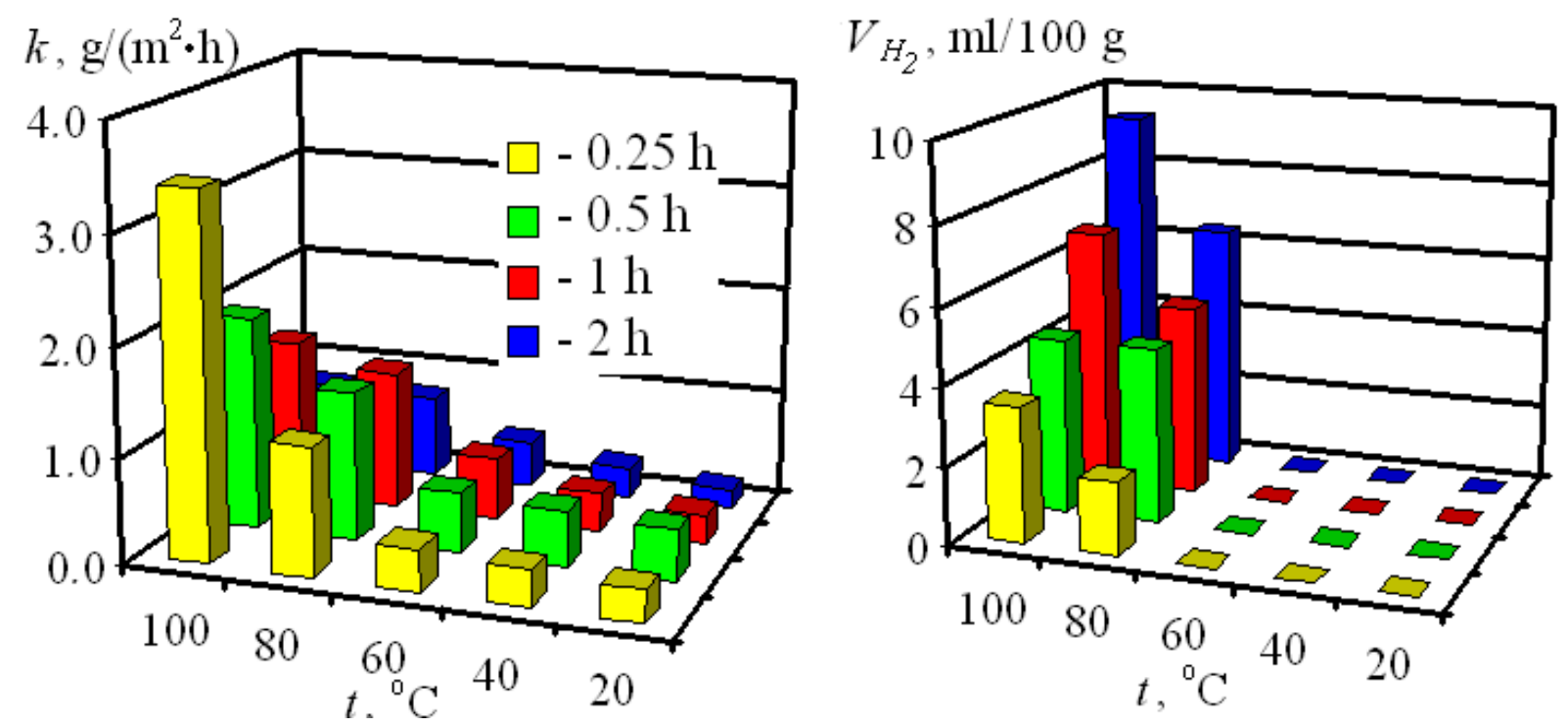

Figure 7. Corrosion rates of steel $1 \mathrm{Kh} 18 \mathrm{~N} 9 \mathrm{~T}$ in $2 \mathrm{M} \mathrm{H}_{2} \mathrm{SO}_{4}+15 \mathrm{mM} \mathrm{H}_{2} \mathrm{~S}$ containing $2.5 \mathrm{mM}$ IFKhAN-92 $+2.5 \mathrm{mM} \mathrm{KI}$ and volume of hydrogen absorbed by the metal as a function of specimen exposure time and solution temperature.

\section{Conclusions}

1. The corrosion rates of chromium-nickel steel $1 \mathrm{Kh} 18 \mathrm{~N} 9 \mathrm{~T}$ in $2 \mathrm{M} \mathrm{H}_{2} \mathrm{SO}_{4}$ in the temperature range of $t=20-100^{\circ} \mathrm{C}$ vary within $1.7-727 \mathrm{~g} /\left(\mathrm{m}^{2} \cdot \mathrm{h}\right)$ and increase with an increase in $t$. Hydrogenation of steel occurs at $t=40-100^{\circ} \mathrm{C}$ and is the strongest at $100^{\circ} \mathrm{C}(12 \mathrm{ml} / 100 \mathrm{~g})$.

2. Addition of $15 \mathrm{mM} \mathrm{H}_{2} \mathrm{~S}$ to $2 \mathrm{M} \mathrm{H}_{2} \mathrm{SO}_{4}$ solution $\left(t=20-100^{\circ} \mathrm{C}\right)$ mostly slows down the corrosion of chromium-nickel steel $1 \mathrm{Kh} 18 \mathrm{~N} 9 \mathrm{~T}$ to rates within $2.8-274 \mathrm{~g} /\left(\mathrm{m}^{2} \cdot \mathrm{h}\right)$. In this case, enhancement of steel hydrogenation to $36 \mathrm{ml} / 100 \mathrm{~g}$ was noted.

3. The fomulation containing $2.5 \mathrm{mM}$ IFKhAN-92 $+2.5 \mathrm{mM} \mathrm{KI}$ can be used for protection of chromium-nickel steel in $\mathrm{H}_{2} \mathrm{SO}_{4}$ solutions, both in the absence and in the presence of $\mathrm{H}_{2} \mathrm{~S}$. It considerably inhibits the metal corrosion in the $\mathrm{H}_{2} \mathrm{~S}$-containing medium up to $100^{\circ} \mathrm{C}$ and completely prevents steel hydrogenation up to $60^{\circ} \mathrm{C}$. This mixture is particularly efficient in solutions without $\mathrm{H}_{2} \mathrm{~S}$, where it inhibits steel corrosion in the entire temperature range studied while keeping the content of hydrogen in the metal at metallurgical level.

\section{Acknowledgements}

This study was financially supported by the Russian Foundation for Basic Research and the Government of the Kaluga Region (Project no. 14-43-03037). 


\section{References}

1. Ya.G. Avdeev, D.S. Kuznetsov, M.V. Tyurina and M.A. Chekulaev, Int. J. Corros. Scale Inhib., 2015, 4, no. 2, 146. doi: 10.17675/2305-6894-2015-4-1-146-161

2. S.M. Beloglazov, Navodorozhivanie stali pri elektrokhimicheskikh protsessakh (Hydrogenation of steel in electrochemical processes), Izdatel'stvo Leningradskogo universiteta, Leningrad, 1975 (in Russian).

3. A.I. Marshakov, A.A. Rybkina, T.A. Nenasheva and M.A. Maleeva, Kondensirovannye sredy i mezhfaznye granitsy (Condensed matter and interphases), 2012, 14, no. 2, 208 (in Russian).

4. A.I. Marshakov and T.A. Nenasheva, Korroz.: mater., zashch., 2004, no. 7, 11 (in Russian).

5. A.I. Marshakov, T.A. Nenasheva, A.A. Rybkina and M.A. Maleeva, Prot. Met., 2007, 43, no $1,77$.

6. L.E. Tsygankova and E.S. Kos'yanenko, Korroz.: mater., zashch., 2006, no. 11, 25 (in Russian).

7. L.E. Tsygankova, A.S. Protasov and D.B. Balybin, Korroz.: mater., zashch., 2008, no. 7, 25 (in Russian).

8. L.E. Tsygankova, A.S. Protasov, D.B. Balybin and N.A. Makol'skaya, Korroz.: mater., zashch., 2009, no. 10, 34 (in Russian).

9. Ya.G. Avdeev, L.V. Frolova, Yu.I. Kuznetsov and O.O. Zel', Korroz.: mater., zashch., 2010, no. 5, 22 (in Russian).

10. Ya.G. Avdeev, L.V. Frolova, D.S. Kuznetsov, M.V. Tyurina and M.A. Chekulaev, Int. J. Corros. Scale Inhib., 2016, 5, no 1, 87. doi: 10.17675/2305-6894-2016-5-1-7

11. J.R. Delorey, D.N. Vician and A.S. Metcalf, SPE Gas Technology Symposium, Calgary, Alberta, Canada, 2002. SPE-75697-MS. doi: 10.2118/75697-MS

12. Zh. Xiao, L.N. Morgenthaler, M. Cowan, K. Aremu and J. Adams, SPE International Symposium on Oilfield Chemistry, The Woodlands, Texas, 2009. SPE-121698-MS. doi: 10.2118/121698-MS

13. D.G. Hill and D.N. DeMott, SPE Symposium on Sour Gas and Crude, Tyler, Texas, USA, 1977. SPE-6660-MS. doi: $10.2118 / 6660-M S$

14. Yu.I. Kuznetsov, Russ. Chem. Rev., 2004, 73, no. 1, 75.

15. E.S. Ivanov, Ingibitory korrozii metallov v kislykh sredakh (Metal Corrosion Inhibitors in Acidic media), Metallurgiya, Moscow, 1986, p. 36 (in Russian).

16. Ya.G. Avdeev, M.V. Tyurina and Yu.I. Kuznetsov, Vestnik Tambovskogo universiteta. Seriya: Estestvennye i tekhnicheskie nauki (Tambov University Reports. Series: Natural and Technical Sciences), 2013, 18, no. 5, 2258 (in Russian). 